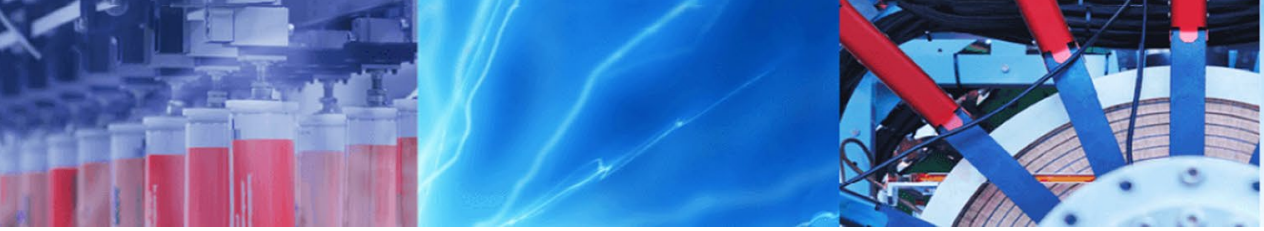

Research Article

\title{
A new application area of electrochemical limiting diffusion current technique: measurement of mixing time and effect of some parameters
}

\author{
Özkan Aydin ${ }^{1} \cdot$ Mehmet Emin Arzutuğ $^{2} \cdot \operatorname{Sinan}$ Yapici $^{3}$
}

(c) Springer Nature Switzerland AG 2019

\begin{abstract}
In this study, the electrochemical limiting diffusion current technique, which was employed first time for the mixing time measurement in the stirred tank system by the authors, was applied to determine the effect of some parameters on the global and local mixing times in the range of $3500 \leq R e \leq 10,000$. The technique well sensed that increasing Reynolds number (Re), blade angle and blade number decreased the mixing time. The most effective parameter was observed to be $\mathrm{Re}$, and the blade number and blade angle, in order. In addition, the mixing time was also investigated for solutions added in various volume fractions having different viscosity and density by using local mixing time measurement. It was determined that the mixing time decreased with the Reynolds number, the ratio of the initial solution volume to the total solution volume and the ratio of kinematic viscosity of the solution in the vessel initially to that of the added one viscosity. The ratio of initial solution volume to total solution volume was found to be a more effective parameter than the others in terms of mixing time.
\end{abstract}

Keywords Mixing time $\cdot$ Stirred vessel $\cdot$ Electrochemical methods $\cdot$ Limiting current $\cdot$ Mixing of miscible liquids

\section{List of symbols}

A Electrode area $\left(\mathrm{m}^{2}\right)$

$C_{\mathrm{Ab}} \quad$ Bulk concentration of active species $\left(\mathrm{mol} / \mathrm{m}^{3}\right)$

$D_{a} \quad$ Agitator diameter $(\mathrm{m})$

$D_{t} \quad$ Tank diameter $(\mathrm{m})$

$F \quad$ Faraday constant $(=96,485 \mathrm{C} / \mathrm{mol}$ or $\mathrm{s} / \mathrm{mol})$

$f_{t} \quad$ Dimensionless mixing factor

$g \quad$ Gravitational acceleration $\left(=9.81 \mathrm{~m} / \mathrm{s}^{2}\right)$

$H \quad$ Solution height $(\mathrm{m})$

$i_{L} \quad$ Limiting current $(\mathrm{A})$

$k_{c} \quad$ Mass transfer coefficient $(\mathrm{m} / \mathrm{s})$

$N \quad$ Rotating speed (rps)

$n \quad$ Blade number

$n_{e} \quad$ Number of transferred electron

$P_{o} \quad$ Power number

RT Rushton turbine
Re Reynolds number

$V_{\text {int }} \quad$ Initial volume of the solution in the vessel (L)

$V_{\text {tot }}$ Total volume of the initial and added solutions (L)

$\phi \quad$ Blade angle $\left(^{\circ}\right)$

$\mu \quad$ Fluid viscosity $(\mathrm{kg} / \mathrm{m} \mathrm{s})$

$v \quad$ Kinematic viscosity $\left(\mathrm{m}^{2} / \mathrm{s}\right)$

$v_{\text {int }} \quad$ Kinematic viscosities of the initial solutions $\left(\mathrm{m}^{2} / \mathrm{s}\right)$

$v_{\text {add }} \quad$ Kinematic viscosities of the added solutions $\left(\mathrm{m}^{2} / \mathrm{s}\right)$

$\theta_{m} \quad$ Mixing time (s)

$\theta_{m, l o c}$ Local mixing time (s)

$\rho \quad$ Fluid density $\left(\mathrm{kg} / \mathrm{m}^{3}\right)$

Sinan Yapici, sinan.yapici@inonu.edu.tr; Özkan Aydin, ozkanaydin@osmaniye.edu.tr; Mehmet Emin Arzutuğ, arzutug@atauni.edu.tr| ${ }^{1}$ Department of Chemical Engineering, Engineering Faculty, Osmaniye Korkut Ata University, 80010 Karacaoğlan, Fakıuşağı, Osmaniye, Turkey. ${ }^{2}$ Department of Chemical Engineering, Engineering Faculty, Atatürk University, 25100 Yakutiye, Erzurum, Turkey. ${ }^{3}$ Department of Chemical Engineering, Engineering Faculty, İönü University, 44280 Battalgazi, Malatya, Turkey. 


\section{Introduction}

Mixing as a discipline started to emerge with the fundamental and practical knowledge going back to 1950 s. The studies about mixing has increased continuously and the investigations during the last 30 years made possible to design a mixing equipment for a process unit [1]. Mixing is one of the basic processes commonly used in chemical, pharmacy, petroleum, food, etc. processes, to get a homogenisation degree at any stage of the process, when necessary $[2,3]$. Stirred vessels are the most commonly used process equipment for mixing purposes.

Mixing time is an important parameter in analysing the effectiveness and hydrodynamic of a vessel, and the time to reach at a certain homogenisation degree after an interruption to the system. The mixing time can generally be defined as the period necessary to achieve a certain degree of homogeneity after adding a tracer into the stirred vessel $[4,5]$. The homogeneity of a system can be explained and determined by the gradients of concentration, temperature, $\mathrm{pH}$, viscosity, colour and phase [1]. The important parameters affecting mixing time in a stirred vessel are the size and geometry of the vessel, the type, geometry, size and speed of impeller, the presence, size, shape and number of baffles, and the physical properties of fluid [6-9].

The principle on which the mixing time is based can be the determination of the change of the properties of the fluid by imposing a tracer effect on the original system; that is, the measurement of the time to achieve a new stable or homogeneous mixture after imposing a tracer effect into the originally stable and homogeneous mixture. Many mixing time measurement techniques have been developed, and the most commonly used ones are conductivity [10], thermographic method [11], colorimetric technique [12], acid-base neutralisation reaction [13], planar laser-induced fluorescence (PLIF) [14], electrical resistance tomography [15], and particle image velocimetry (PIV) [16]. Every technique has its own advantages and disadvantages. A good review of these techniques and their comparisons are given by Ascanio [17].

However, for the measurement of mixing time, a novel and new measurement method in addition to the conventional ones was developed and proved by Aydin and Yapici [18], which is based on electrochemical limiting diffusion current technique (ELDCT). In their work they proved that this method is simple, cheap, flexible, straightforward and fast, and also able to measure mixing time both locally and globally in both intrusive and non-intrusive mode.

The purpose of the present work is to investigate the effect of fluid viscosity, blade number and blade angle on the mixing time in a four-baffled stirred vessel agitated by a Rushton turbine type impeller, and further prove that ELDCT is a good way of measuring mixing time, by employing this recently developed method it for this sort of measurements, which is a new application field for the technique. Another aim of the present work is to measure mixing time by adding a liquid with different viscosity in large amount into the main fluid present in the vessel; that is, mixing of two fluids having different viscosities. The reason to do this is the fact that this sort of mixing be encountered commonly in industrial operations, and therefore, to get an insight of mixing time for the systems of this kind.

\section{Theoretical background}

\subsection{Mixing time in stirred tank}

From a globally mixing point, the bulk mixing time for a stirred vessel is the necessary period required to get the tracer uniformly distributed throughout the vessel.

$\theta_{m}=\frac{K}{N}$

where $\theta_{m}$ is the mixing time, $K$ is a constant depending upon the flow regime in the vessel, and the size, geometry of the vessel including impeller, and $N$ is the impeller speed in revolution per second [19]. $K$ can be approached to be constant in the laminar and turbulent regimes, but not in the transition regime. Mixing time can be correlated in dimensionless form as a function of Reynolds number [20]

$N \theta_{m}=\alpha(\operatorname{Re})^{\beta}$

where $a$ and $\beta$ are the parameters depending on system parameters, and Re is the Reynolds number expressed as follow:

$\operatorname{Re}=\frac{\rho N D_{a}^{2}}{\mu}$

where $\rho$ is the density of fluid; $D_{a}$ is the impeller diameter and $\mu$, the dynamic viscosity of fluid. For a stirred vessel with common type impellers, the flow regime is laminar for $\operatorname{Re}<10$, turbulent for $\operatorname{Re}>1 \times 10^{4}$, and transitional in the range of $10 \leq \operatorname{Re} \leq 1 \times 10^{4}$ [21].

Turbine impeller can be classified by the flow type in vessel which it produces [1]. Concentrically positioned turbine impeller having a blade angle of $90^{\circ}$ generates radial flow while it produces both radial and axial flow simultaneously if the blade angle is different than $90^{\circ}$. 
For a turbine impeller, the dimensionless mixing factor can be defined as.

$f_{t}=\theta_{m} \frac{\left(N D_{a}^{2}\right)^{2 / 3} g^{1 / 6} D_{a}^{1 / 2}}{H^{1 / 2} D_{t}^{3 / 2}}$

where $f_{t}$ is dimensionless mixing factor, $D_{t}$ vessel diameter (m); $g$, gravitation constant $\left(\mathrm{m} / \mathrm{s}^{2}\right)$; and $H$, the height of liquid in the vessel $(\mathrm{m})$. If one considers the change of $f_{t}$ with $\mathrm{Re}$, it is seen that it changes from approximately 700 to 7 as Re goes up from 1 to $10^{3}$ while it changes, in a very narrow range, approximately from 7 to 4 when Re increases considerably from $10^{3}$ to $10^{6}$. Therefore, for $\operatorname{Re}>1000, f_{t}$ can approximately be taken as constant [21].

Paul et al. [1] gives the following equation for the mixing time in transient regime as a function of power number, Re, impeller and tank diameters

$N \theta_{m}=\frac{183^{2}}{P_{o}^{2 / 3} \operatorname{Re}}\left(\frac{D_{t}}{D_{a}}\right)^{2}$

where $P_{o}$ is dimensionless power number.

\section{Experimental technique}

\subsection{Materials and method}

There are many studies on the theory and application of ELDCT in the literature [22-26]. The application of ELDCT for the measurement of mixing time, which is a new application field, is given in detail by Aydin and Yapici [18]. If briefly explained, for the ELDCT conditions, the concentration of active ion on the electrode surface is practically zero due to rapid electrochemical reaction on the surface, for which the relation between limiting current and system parameters takes the following form:

$i_{L}=k_{c} C_{A b} A n_{e} F$

where $A$ is electrode area (cathode), $\mathrm{m}^{2} ; c_{A b}$, concentration of active ion in bulk solution, $\mathrm{mol} / \mathrm{m}^{3} ; F$, Faraday constant, $(=96,485 \mathrm{C} / \mathrm{mol}) ; k_{c}$ convective mass transfer coefficient, $\mathrm{m} / \mathrm{s} ; i_{L}$, limiting current, $A$.

If the system is operated under a fixed hydrodynamic condition, electrode surface area; consequently mass transfer coefficient is also become a constant. Under these conditions, changing bulk solution results in a change in the limiting current value. So by following the limiting current during the period for the system to get from one uniform condition to the after injecting tracer, the mixing time can be determined.
For the electrochemical system, the well-known potassium ferri/ferro cyanide couple supported by the inert electrolyte of potassium carbonate was employed, which is the most suitable and widely applied system for this kind of studies [27], and has the following reaction at the electrodes.

$\left[\mathrm{Fe}(\mathrm{CN})_{6}\right]^{3-}+e^{-} \rightarrow\left[\mathrm{Fe}(\mathrm{CN})_{6}\right]^{4-}$ at cathode

$\left[\mathrm{Fe}(\mathrm{CN})_{6}\right]^{4-} \rightarrow\left[\mathrm{Fe}(\mathrm{CN})_{6}\right]^{3-}+\mathrm{e}^{-}$at anode

The chemicals used in the measurement were MERCK made, analytic grade with purity higher than $\% 99$. The initial electrolyte consisted of a solution $0.0002 \mathrm{M}$ of ferricyanide, $0.0008 \mathrm{M}$ of ferrocyanide and $0.1 \mathrm{M}$ of $\mathrm{K}_{2} \mathrm{CO}_{3}$, which is supporting electrolyte. The composition of tracer solution was $0.1 \mathrm{M} \mathrm{K}_{3} \mathrm{FCN}_{6}, 0.4 \mathrm{M} \mathrm{K}_{4} \mathrm{FCN}_{6}$ and $0.1 \mathrm{M} \mathrm{K}_{2} \mathrm{CO}_{3}$. The concentration of the solution was so arranged that the system becomes a cathodic controlled process; for this purpose the concentration of ferricyanide reduced at the cathode was kept one-fourth of that of ferrocyanide, and furthermore the area of the anode was arranged to be at least 3 times larger than that of the cathode. For global mixing time measurement, one baffle was used as cathode while the other three were used as anode.

The experiments for the determination of the over potential difference corresponding to about the plateau value of the limiting current were performed for two electrolyte solutions, namely the solutions with 0 and $50 \%$ glycerol at 6 different rotation speed (60-890 rpm) and for 5 different active ion concentrations $(0.0008-0.0040 \mathrm{M})$, and was determined to be $-0.35 \mathrm{~V}$.

\subsection{Experimental}

The experiments were carried out in the cylindrical vessel with an inner diameter of $150 \mathrm{~mm}$ which was made of Plexiglass material having a cooling/heating jacket around it. The $60 \mathrm{~mm}$ diameter Rushton turbine used as a mixer was placed concentrically, for which the ratio of the impeller diameter to the vessel's is 0.4 , and four baffles made of nickel were equally spaced into the tank. The height of the solution in the vessel was kept equal to the inner diameter of the vessel.

The experiments were performed in two series. In the first series, it was aimed to measure the effect of the blade number and blade angle of a Rushton type impeller on mixing time, by employing global mixing time measurements, for which one baffle was used as sensor while the other three as counter electrode [18]. In the second part of the experiments, the purpose was to measure the mixing time when a large amount of liquid having a 
Fig. 1 Stirred vessel with baffles used in measurements [18]

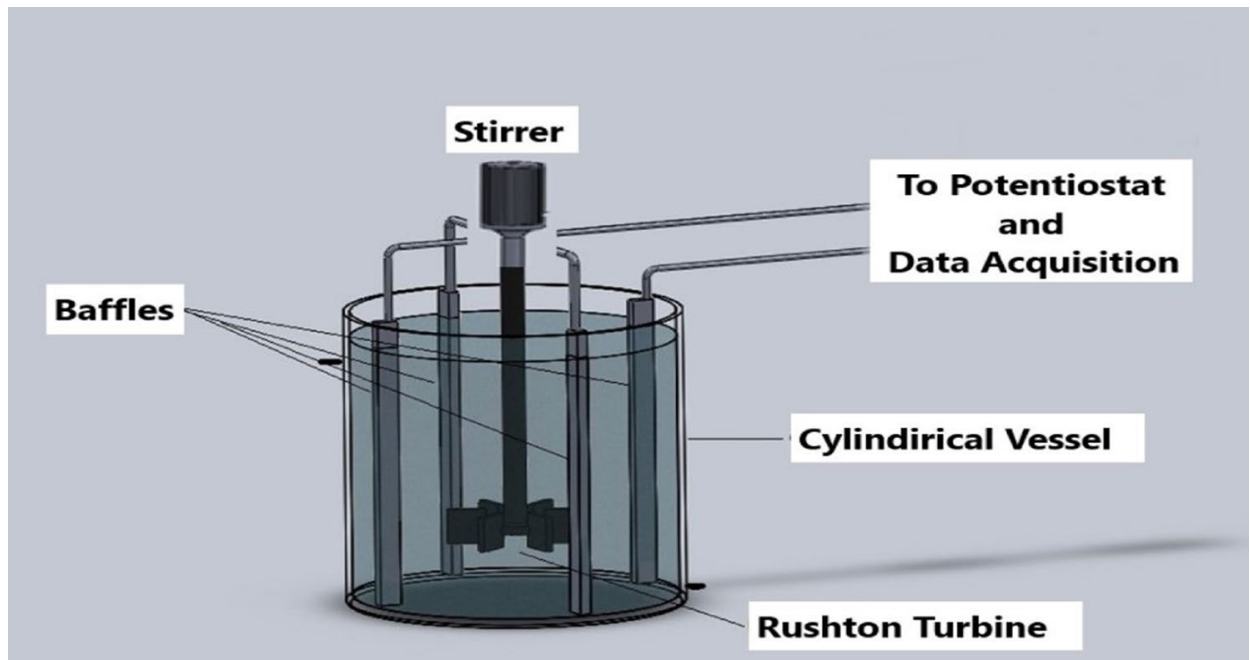

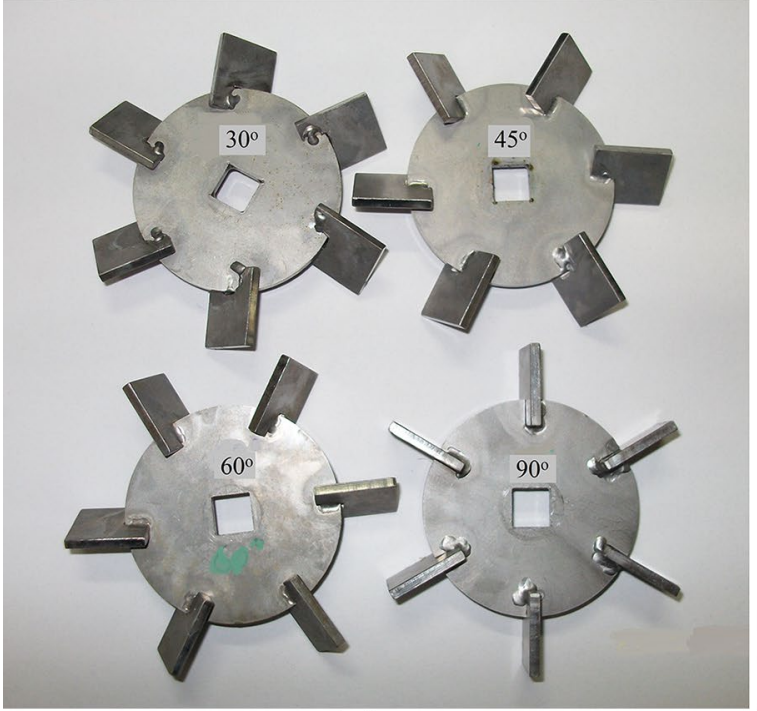

(a)

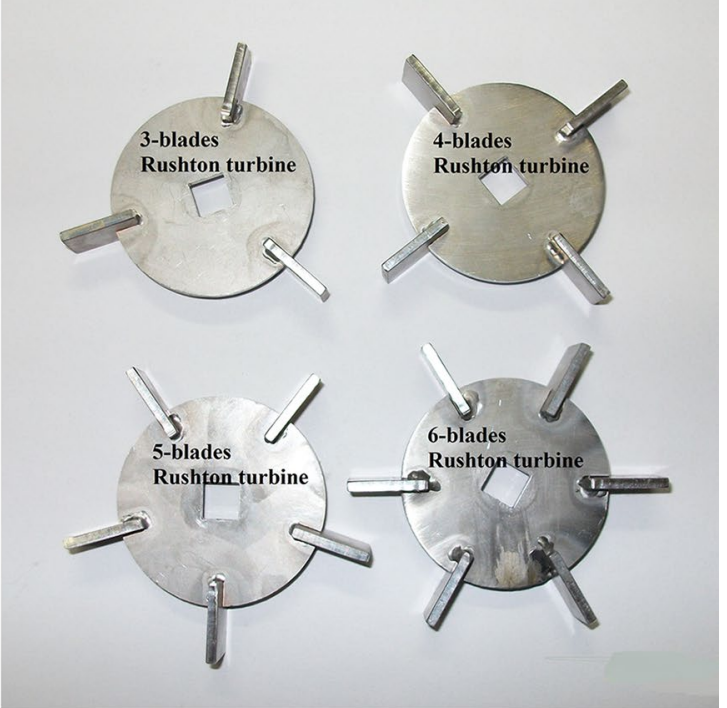

(b)

Fig. 2 Rushton turbine type impeller having a different vane angle and $\mathbf{b}$ different vane number

different viscosity than that of the main liquid in the vessel was added in the vessel, which is a situation commonly encountered in industrial applications; that is mixing time of two different solutions in large proportion. For the second group, the local electrode was employed to measure mixing time since the total volume, therefore the active area of baffle used as cathode, was changed with the addition of second solution into the vessel.

The standard size ratios and details of the stirred vessel can be found in Geankoplis [21], and its schematic drawing is given in Fig. 1. The temperature was kept constant by circulating thermostat and all the experiments were performed at $20 \pm 0.5^{\circ} \mathrm{C}$. The stirring speed was adjusted by a digital controlled stirrer of Servodyne, 50003-00 model.
The impeller for the mixing was turbine one of Rushton type having a diameter of $60 \mathrm{~mm}$. Four different blade angle of $30^{\circ}, 45^{\circ}, 60^{\circ}$ and $90^{\circ}$, and for different blade number of 3, 4, 5 and 6 were employed to investigate the effect of the blade angle and number on mixing time (see Fig. 2). The height of the fluid was taken equal to the diameter of the vessel. The impeller was so located that it was centred axially within the vessel and its height from the bottom of tank became $50 \mathrm{~mm}(=\mathrm{H} / 3)$.

For the electrochemical measurement, GAMRY made (Interface 1000) potentiostat/galvanostat was used and the readings were recorded by a computer to process data. After starting the experiment, a tracer of $5.2 \mathrm{~mL}$ was added into a solution of $2600 \mathrm{~mL}$ just at the 60th second, the 
Table 1 Viscosity and density values of solutions used in experiments

\begin{tabular}{lll}
\hline $\begin{array}{l}\text { Glycerol ratio of solution } \\
(\%)(w / w)\end{array}$ & Viscosity $(\mathrm{cP})$ & Density $(\mathrm{g} / \mathrm{mL})$ \\
\hline No glycerol & 1.0545 & 1.0115 \\
10 & 1.3100 & 1.0220 \\
20 & 1.8170 & 1.0550 \\
30 & 2.5687 & 1.0820 \\
40 & 3.7280 & 1.1050 \\
50 & 6.1070 & 1.1393 \\
\hline
\end{tabular}

change in limiting current was recorded, and the graph of the change was analysed by Boltzmann fitting method to determine the mixing time.

In the second series of the experiments, the mixing time in the a system with the addition of a solution having different properties in considerably larger proportions; the volume ratio of the added solution into the vessel with regards to the total amount changed between 10 and $30 \%$. The mixing time measurement was carried out with a local electrode of $10 \mathrm{~mm}$ diameter. The experiments were performed in a similar manner mentioned above as the first series of experiments, except the addition of a solution having different viscosity, and in large amount. The temperature and stirring speed were kept constant at $20^{\circ} \mathrm{C}$ and $100 \mathrm{rpm}$, respectively. However Reynolds number changed due to the solutions having different thermophysical properties. The sum of the solution initially present in the vessel plus the one which was added into it was so arranged that it be constant at $2600 \mathrm{~mL}$. The solutions used in this experiments were again the electrolytes with glycerol ranging from 0 to $50 \%$ in weight. The viscosity and density values of the solutions are given in Table 1.

The tip position of the local electrode in the vessel was $90 \mathrm{~mm}$ height from the bottom and $37.5 \mathrm{~mm}$ away from the side wall and it was so arranged that the tip point became on the radial line from the midst of two neighbouring baffles to axial centre of the vessel. Though these measurements the global mixing time values were not obtained, it gives an idea about the effects of the volumes and viscosities of the initial solution in the vessel and the added solution into it on mixing time. All the experiments were repeated at least twice, and their arithmetic averages were used in the calculations.

As an example for the ratios of the original solution initially present in the vessel and the solution added onto it is given in Table 2. The stirring speed values corresponding to the Reynolds numbers for each solution is given in Table 3. The Reynolds number range corresponds to the transitional regime range for stirred vessels.
Table 2 An example for proportions of original solution initially present in vessel and solution added onto it

\begin{tabular}{llllll}
\hline $\begin{array}{l}\text { Initial } \\
\text { solution, } \\
\text { glycerol } \\
(\%)(w / w)\end{array}$ & $\begin{array}{l}\text { Added } \\
\text { solution, } \\
\text { glycerol } \\
(\%)(w / w)\end{array}$ & $\begin{array}{l}\text { Volume } \\
\text { ratio of } \\
\text { added } \\
\text { solution } \\
(\%)(v / v)\end{array}$ & $\begin{array}{l}\text { Volume } \\
\text { of added } \\
\text { solution } \\
(\mathrm{mL})\end{array}$ & $\begin{array}{l}\text { Volume } \\
\text { of initial } \\
\text { solution } \\
(\mathrm{mL})\end{array}$ & $\begin{array}{l}\text { Total } \\
\text { volume } \\
(\mathrm{mL})\end{array}$ \\
\hline 50 & 30 & 10 & 260 & 2340 & 2600 \\
50 & 30 & 20 & 520 & 2080 & 2600 \\
50 & 30 & 30 & 780 & 1820 & 2600 \\
\hline
\end{tabular}

\section{Results and discussion}

\subsection{Effect of blade angle}

These measurements were performed to investigate the effect of blade angle on the mixing time for the blade angles of $30^{\circ}, 45^{\circ}, 60^{\circ}$ and $90^{\circ}$ of a Rushton turbine stirrer for $60 \mathrm{~mm}$ impeller diameter with 6 blades. The impeller diameter and blade number were kept constant. The experiments were carried out for the solutions with glycerol of 10, 20, 30, 40 and 50\%, and with no glycerol. All measurements were repeated twice and their arithmetic averages were used in the analyses. The change in the limiting current values with the addition of tracer are shown in Fig. 3, as an example, for the recordings mixing time in the solution with no glycerol for $90^{\circ}$ blade angle at different stirring speeds. The time difference between the addition of tracer and reaching at new steady state was taken as mixing time for the given experimental conditions.

For the other experimental conditions in the range mentioned above, the limiting current recordings were also taken and then mixing time values were determined, and finally the results were demonstrated in graphs as given in Fig. 4, which presents the results for the solutions of 6 different viscosities.

Figure 4 shows that increasing Reynolds number has an effect of reducing mixing time. For the same Reynolds number the mixing time values are quite close each other for the solutions having different viscosities at the same blade angle. The differences are due to the fact that the constant $K$ in the equation of $\theta_{m} N=K$ is not exactly constant for the transient flow regime.

To be able to see the effect of blade angle more clearly, the mixing time values for the solution with no and 50 per cent glycerol, as an example, are presented in the graph of mixing time versus blade angle in Fig. 5 . As seen in this figure, there is a slight effect of the blade angle on mixing time, and increasing blade angle causes a decrease in mixing time value. This effect is more pronounced at low Reynolds number values and diminishes as Reynolds number increases. 
Table 3 Reynolds numbers corresponding to stirring speeds for each solution

\begin{tabular}{lcccccc}
\hline Glycerol $(\%)(w / w)$ & \multicolumn{2}{l}{ Stirring speed $(\mathrm{rpm})$} \\
\cline { 2 - 6 } $\operatorname{Re}$ & \multicolumn{1}{c}{0} & 10 & 20 & 30 & 40 & 50 \\
\hline 3500 & 60 & 70 & 100 & 140 & 200 & 310 \\
5200 & 90 & 110 & 150 & 210 & 290 & 460 \\
6900 & 120 & 150 & 190 & 270 & 390 & 620 \\
8600 & 150 & 180 & 240 & 340 & 480 & 770 \\
10,000 & 180 & 210 & 280 & 400 & 560 & 890 \\
\hline
\end{tabular}

Fig. 3 Mixing time in the solution with no glycerol for the impeller of $90^{\circ}$ blade angle of 6 blades and impeller diameter of $60 \mathrm{~mm}$ at different stirring speeds

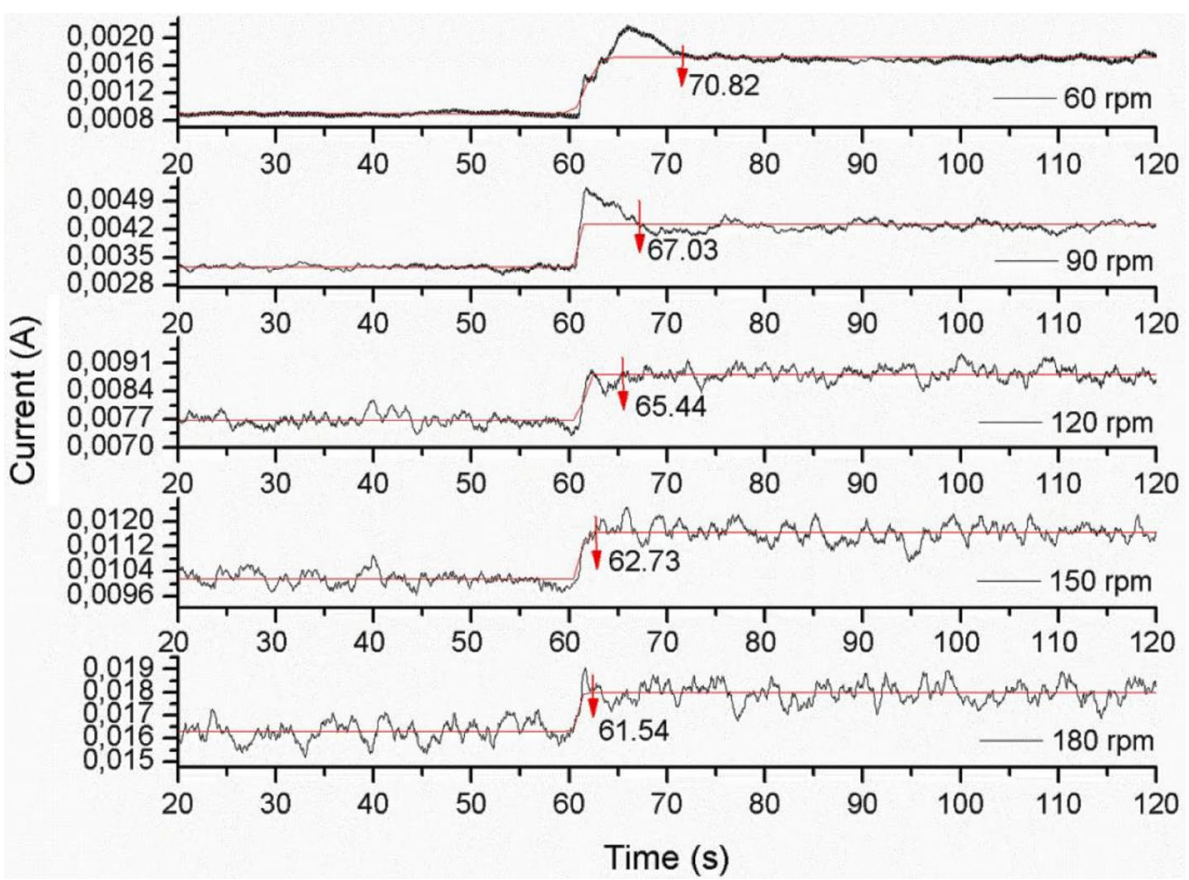

\subsection{Effect of blade number}

To investigate the effect of the blade angle on mixing time, a Rushton type turbine with an impeller diameter of $60 \mathrm{~mm}$ and blade angle of $90^{\circ}$ was used; the blade numbers were chosen as $3,4,5$ and 6 . Figure 6 gives the recordings of the change in limiting current values with the addition of tracer, for the blade number of 3 at 5 different rotating rates of the impeller.

The mixing time values at different blade number from these recordings are given in Fig. 7 in graphs. These graphs show that increasing blade number has a decreasing effect on mixing time at a given Reynolds numbers. It seems that this effect is more pronounced at low Reynolds numbers and shows a tendency of gradually diminishing as Reynolds number increases. This can be explained by the fact that the interaction between moving solid surface and solution results in more mixing and higher turbulence with increasing blade number.

Figure 8 gives a different insight of the change of mixing time with blade number at given Reynolds numbers, for the solutions with no glycerol and $30 \%$ glycerol, as examples. These graphs show more clearly the effect of blade number on mixing time. For the other solutions, similar behaviour was observed as well.

An empirical equation was developed, which includes the effect of blade number and blade angle, in addition to Reynolds number, by analysing all the data with Statistica programme within $95 \%$ confidence interval. The 


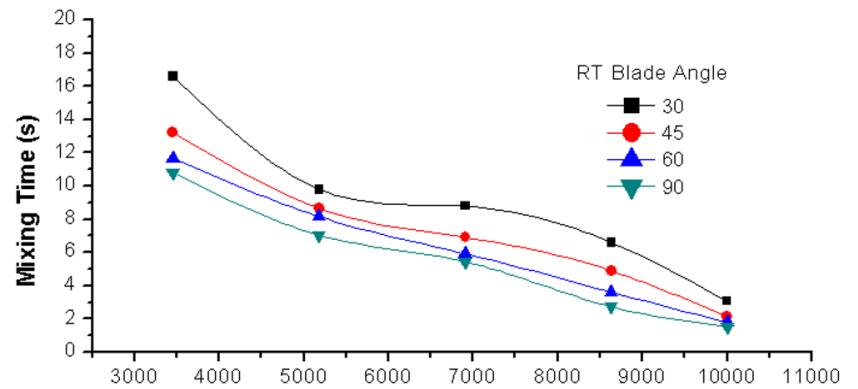

$\operatorname{Re}$

(a)

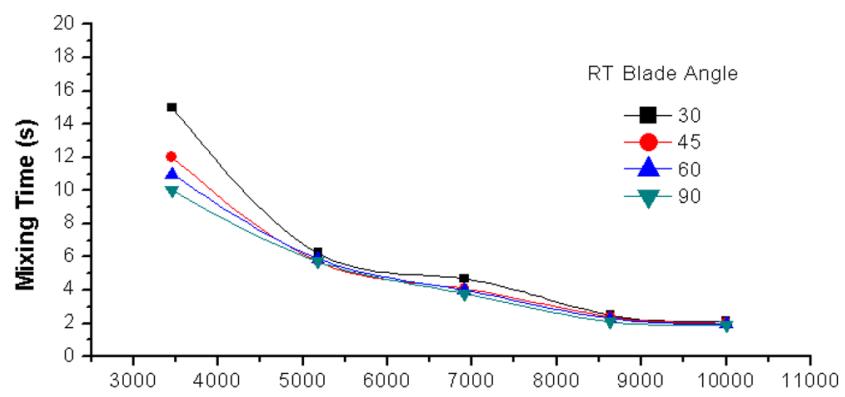

$\operatorname{Re}$

(c)

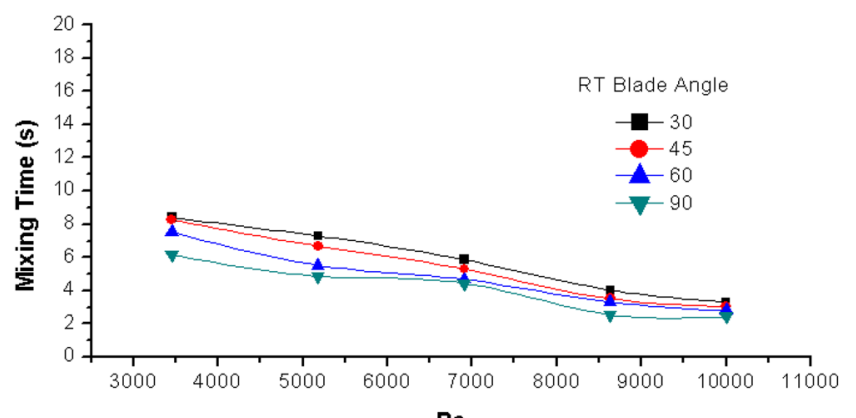

(e)

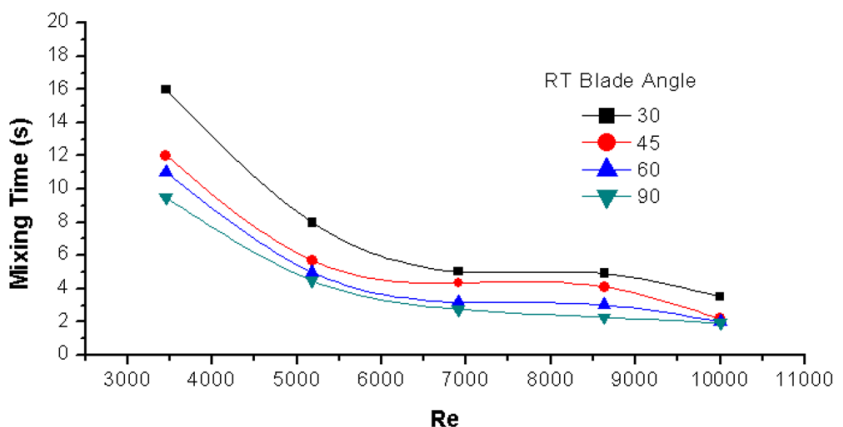

(b)

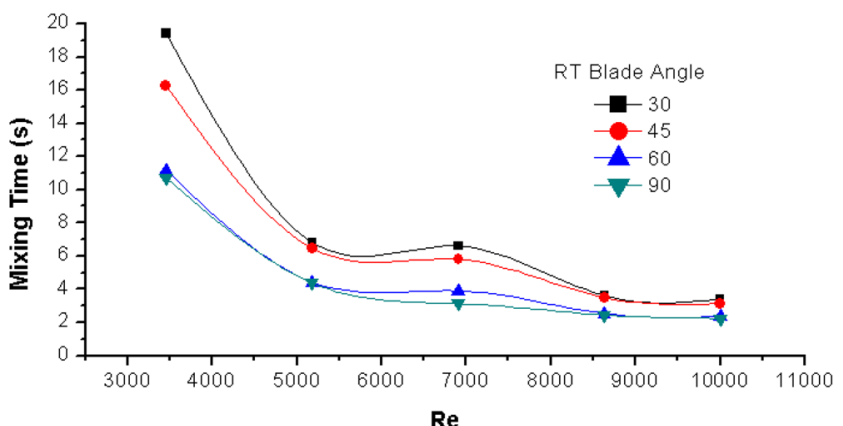

(d)

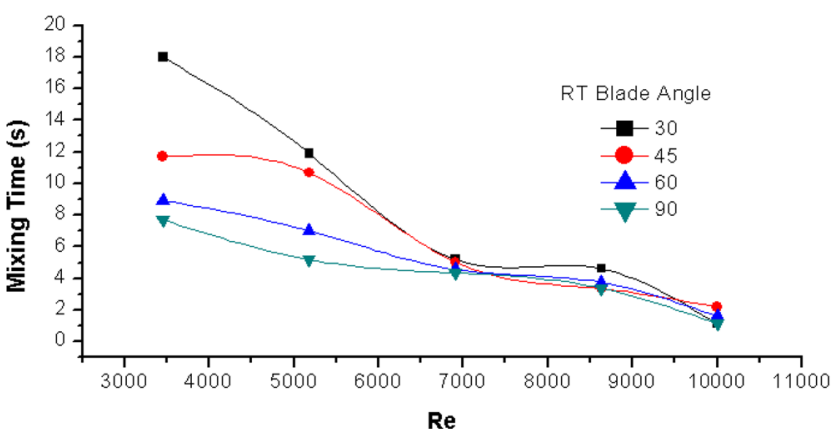

(f)

Fig. 4 Change of mixing time values with Reynolds number for different blade angles for solutions a with no glycerol, b with $10 \%$ glycerol, c with $20 \%$ glycerol, d with $30 \%$ glycerol, e with $40 \%$ glycerol and $\mathbf{f}$ with $50 \%$ glycerol

analysis gave the following equation with a regression coefficient value of $R=0.9410$,

$\theta_{m}=k_{1} \operatorname{Re}^{-1.13} \phi^{-0.42} n^{-0.59}$

where $\theta_{m}$ is the mixing time $(\mathrm{s}) ; k_{1}=7.36 \times 10^{6} \mathrm{~s}$ for the present vessel and impeller type, a coefficient which might depend on type of vessel and impeller, and flow regime; $\phi$, blade angle $\left({ }^{\circ}\right) ; n$, blade number.

In the literature the power of Reynolds number for transition region is given as -1.0 [1]. The power of this correlation is quite close to that of the literature. However, when the power of Reynolds number was fixed at -1 , the correlation takes the following form with a little bit low regression coefficient of $R=0.9201$.

$\theta_{m}=k_{2} \operatorname{Re}^{-1.0} \phi^{-0.50} n^{-0.70}$

In this case $k_{2}=7.97 \times 10^{5} \mathrm{~s}$. The predictions of the correlation in Eq. (9) are compared with the experimental data in Fig. 9; the predicted results exhibited an average deviation within $11.5 \%$ from those of measured ones. 
Fig. 5 Mixing time change with blade angle for solutions without and with $50 \%$ glycerol, a solution with no glycerol and $\mathbf{b}$ solution containing $50 \%$ glycerol

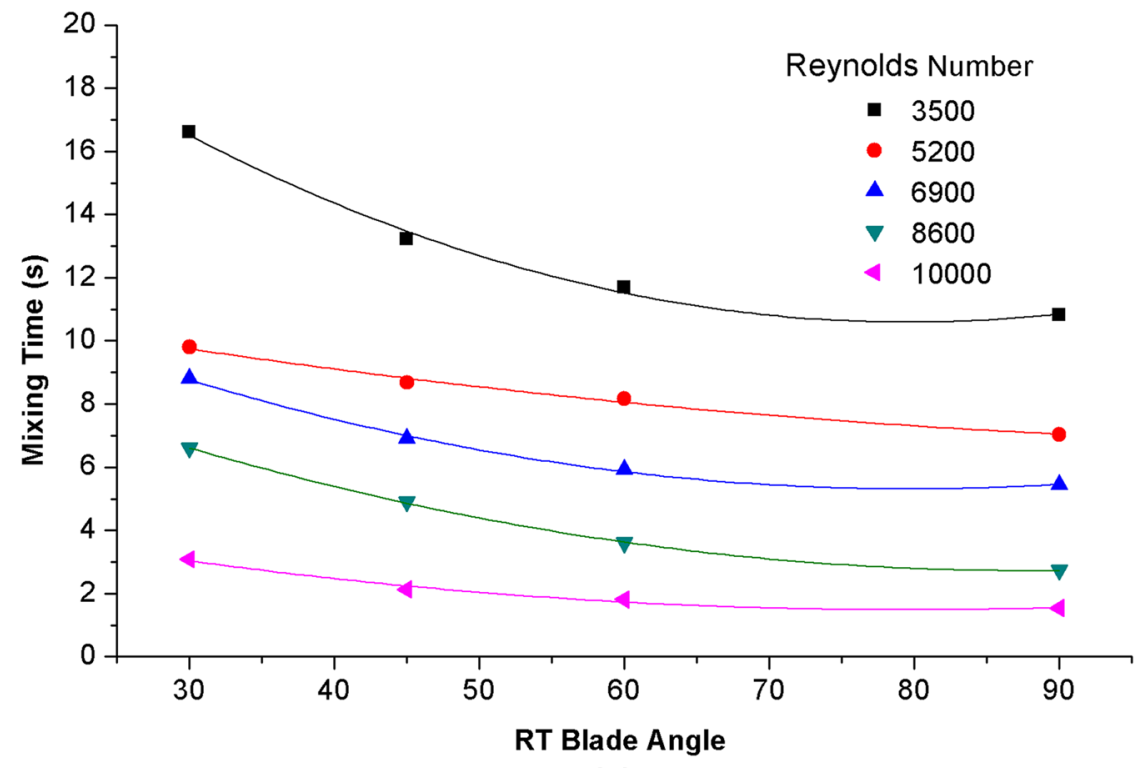

(a)

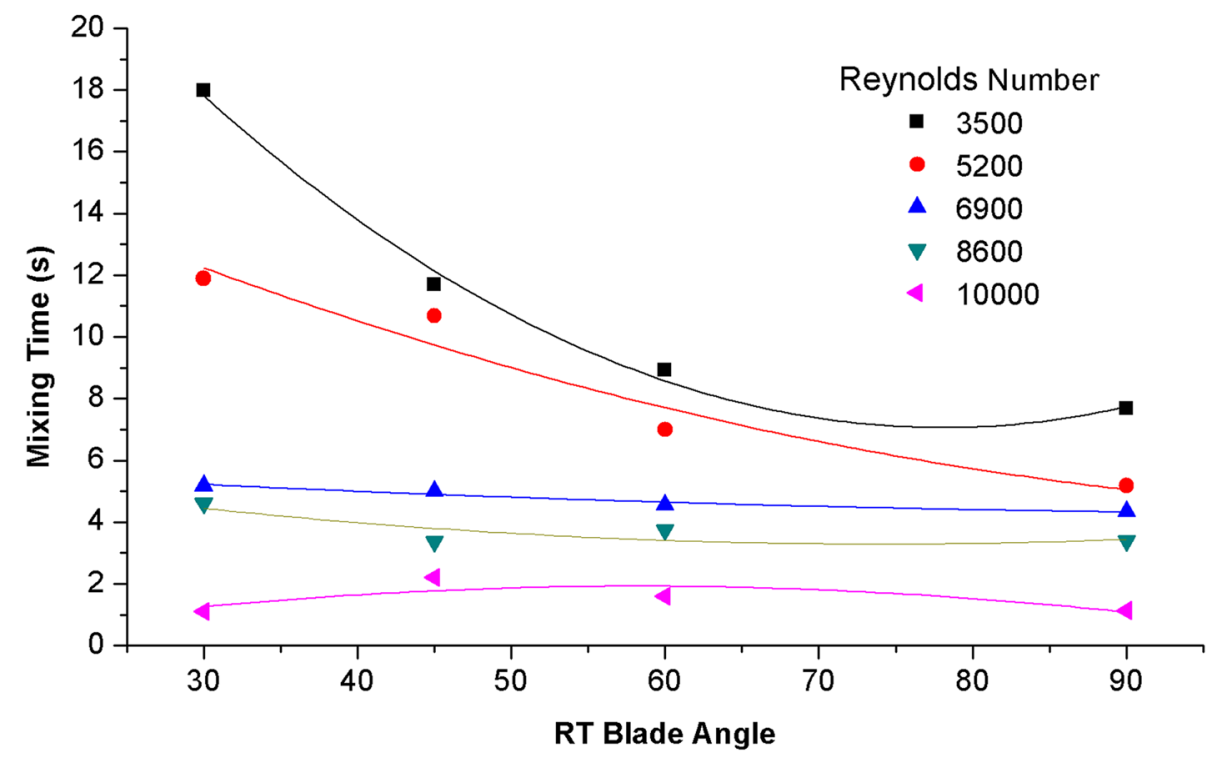

(b)

\subsection{Mixing factor}

Combining Eqs. (4) and (10) gives the dimensionless mixing factor for a Rushton turbine type impeller having different blade angles and numbers ranging $30^{\circ}-90^{\circ}$ and $3-6$, respectively: $f_{t}=k_{2} \frac{g^{1 / 6} v}{\phi^{0.50} n^{0.70}} \frac{\left(D_{a} / H\right)^{1 / 2}}{\left(N D_{a}^{2}\right)^{1 / 3} D_{t}^{3 / 2}}$

The change in $f_{t}$ with Re is given in Fig. 10 as the averaged values of $f_{t}$ for each Reynolds versus Re. As seen from 
Fig. 6 Recordings of limiting current change with addition of tracer for solution of no glycerol at different rotating speeds, using impeller with 3 blades, $90^{\circ}$ blade angle

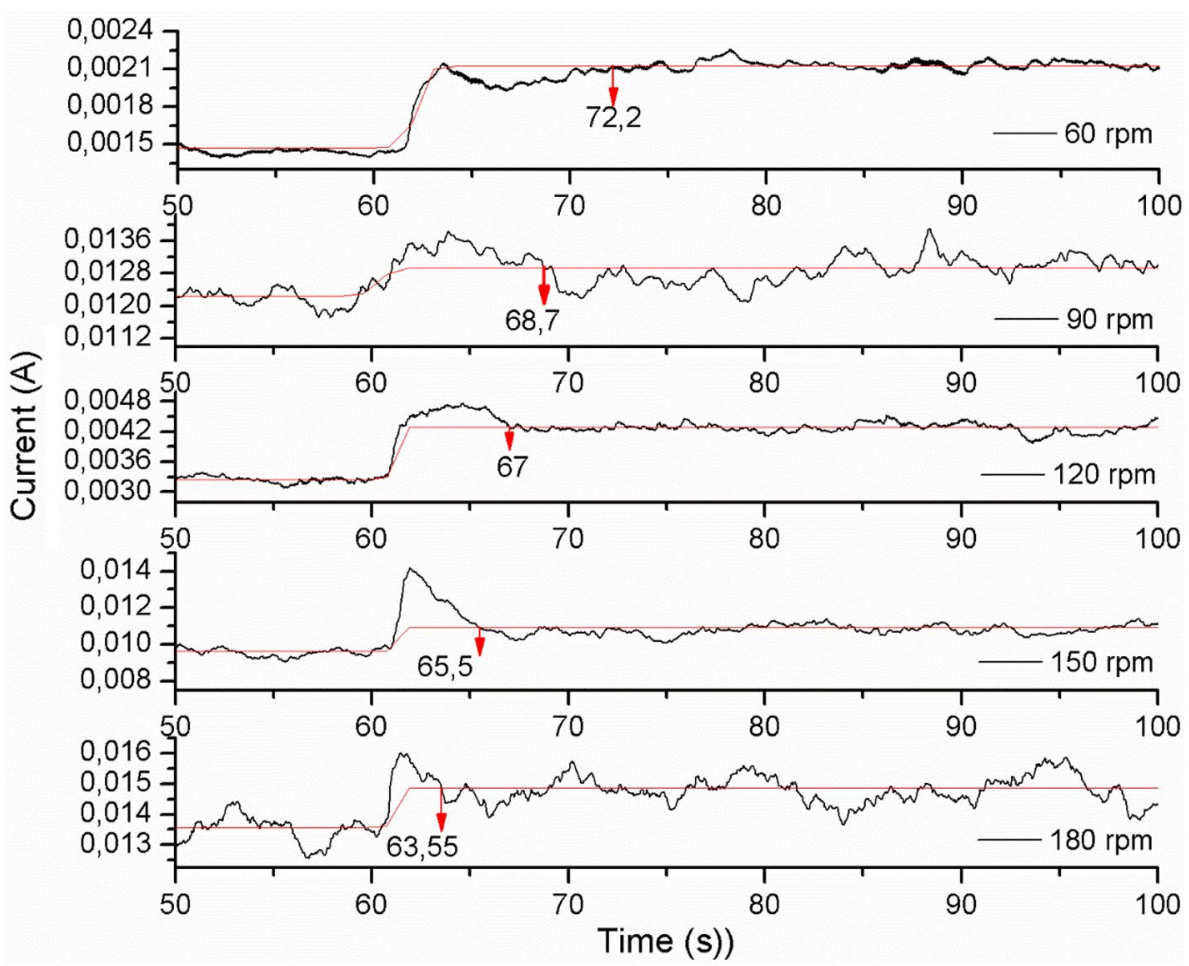

this graph, the value of $f_{t}$ goes from approximately 6 to 4 as Re goes from $3 \times 10^{3}$ to $10^{4}$, showing very good agreement with the values of the correlation given in Geankoplis [21]. This result also proves the validity of ELDCT for the mixing time measurement.

\subsection{Local mixing time of bulk mixing of solutions with different viscosities}

In this series of the experiments, it was aimed to observe the mixing time values for the solutions of having different viscosity values and of mixed in bulk volumes. A solution in large amount between 10 and $30 \%$ of the total solution, instead of in trace amounts, was added to the main solution initially present in the vessel. For this purpose, the experiments given in Table 4 were carried out; the corresponding mixing time values are given in the same table. The sum of the initial solution plus the one which added into it was kept constant at $2600 \mathrm{~mL}$. For the sake of simplicity, the physical properties of the initial solution used for the calculation of the Reynolds number, because the values and physical properties of the vessel content were changed after the addition of new solution, depending upon the amount and properties of the added solution. Though the stirring speed was kept constant at $100 \mathrm{rpm}$, Reynolds number changed due to the changes in the viscosity and density values of the solutions.

Although these measurements give mixing time values at a certain location, not the global ones, it gives an idea about the effects of the volumes and viscosities of the initial solution in the vessel and the added solution into it.

Some attempts were made to correlate the local mixing times with the Reynolds number, kinematic viscosities of each solutions separately, volume ratios of the initial and added to the total volume, and it was observed that the volume ratio of the added solutions has almost no effect in the investigated range, and that the power of the kinematic viscosities have almost the same value, but the signs are opposite. Thus the local mixing times were correlated by taking into account the Reynolds number on the basis of the initial solution, the volume ratio of the initial solution to the total's 


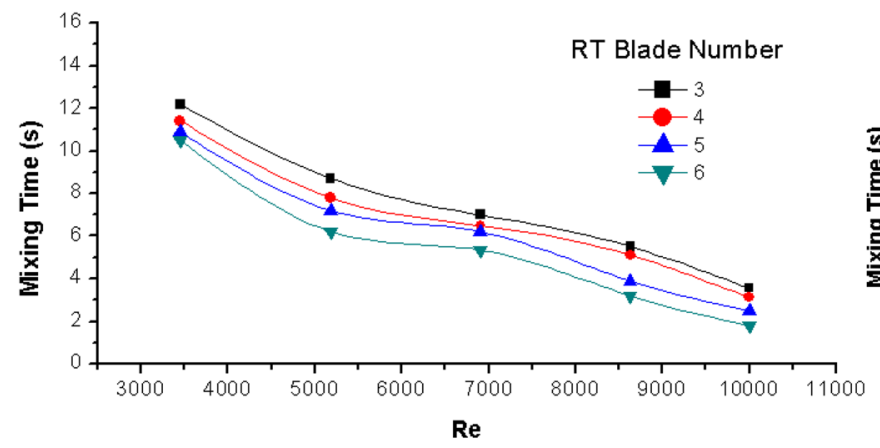

(a)

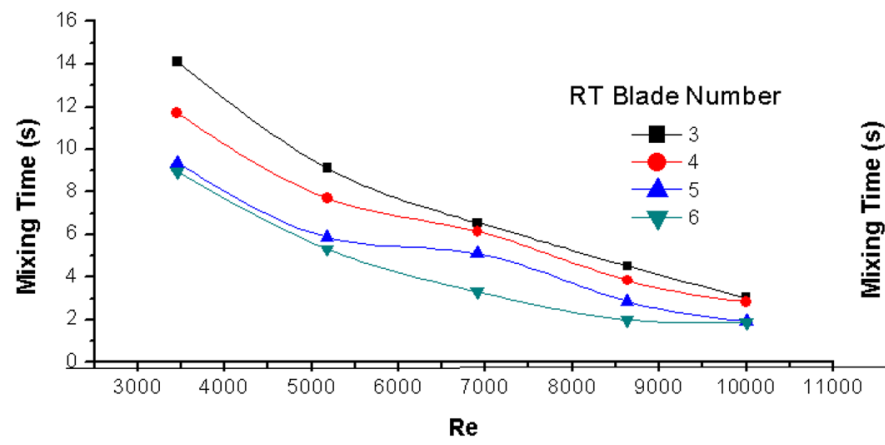

(c)

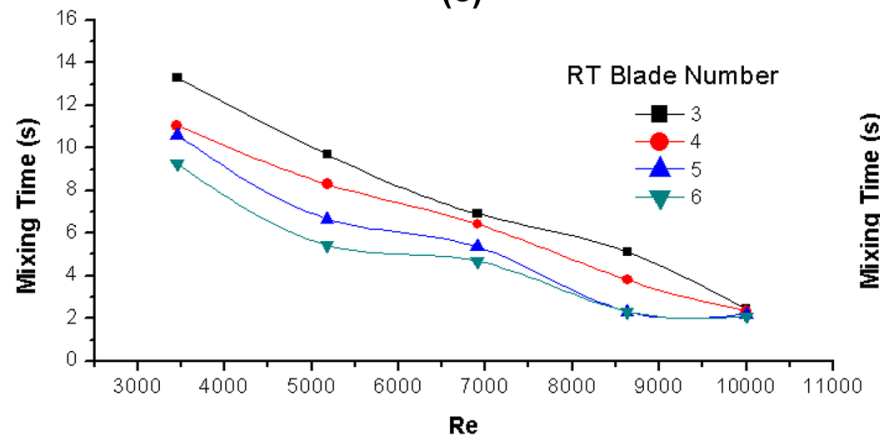

(e)

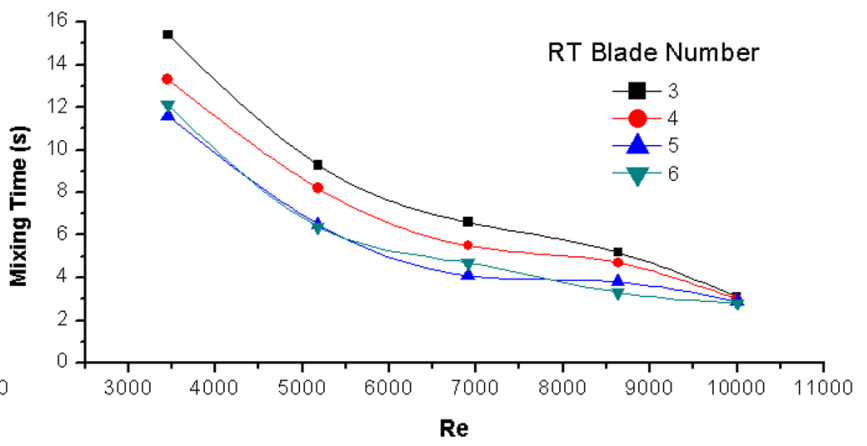

(b)

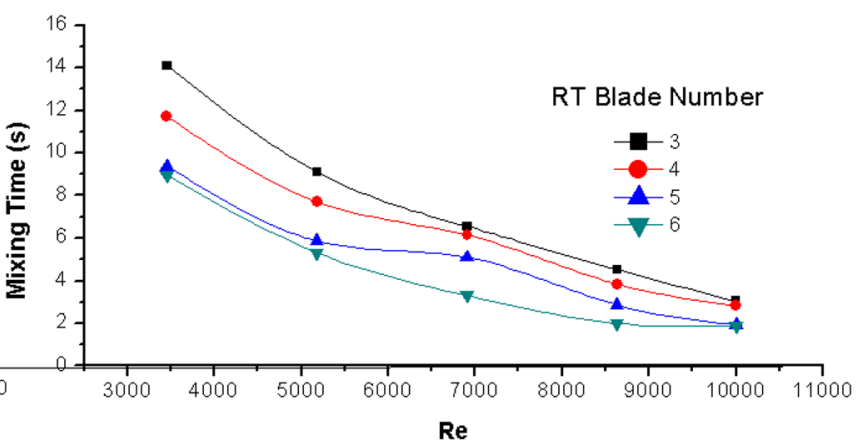

(d)

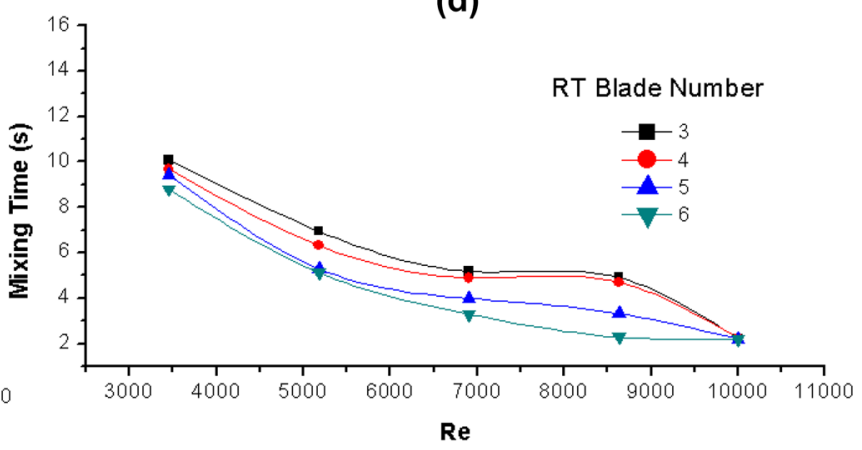

(f)

Fig. 7 Effect of blade number on mixing time at different Reynolds numbers for 6 different solutions, a with no glycerol, b with $10 \%$ glycerol, c with $20 \%$ glycerol, d with $30 \%$ glycerol, e with $40 \%$ glycerol and f with $50 \%$ glycerol

and the ratio of viscosities of the initial's to the added one, and the following correlation was obtained with a regression coefficient of 0.8603 .

$\theta_{m, \text { loc }}=k_{3} \operatorname{Re}_{\mathrm{int}}^{-0.62}\left(\frac{V_{\text {int }}}{V_{\text {tot }}}\right)^{-2.17}\left(\frac{v_{\text {int }}}{V_{\text {add }}}\right)^{-0.35}$

where $\theta_{m, l o c}$ is the local mixing time, $s ; k_{3}=612.3 \mathrm{~s}$, a coefficient dependent upon vessel and impeller type, and flow regime; $V_{\text {int }}$ is the initial volume of the solution in the vessel, $L ; V_{\text {tot }}$ is the total volume of the initial and added solutions, $\mathrm{L} ; v_{\text {int }}$ and $v_{\text {add }}$ are the kinematic viscosities of the initial and the added solutions, $\mathrm{m}^{2} / \mathrm{s}$, respectively. When the analysis repeated with the Reynolds number based on the properties of the end solution, the correlation takes the following form with a little higher regression coefficient of 0.8701 .

$\theta_{m, l o c}=k_{4} \operatorname{Re}_{\text {end }}^{-0.60}\left(\frac{V_{\text {int }}}{V_{\text {tot }}}\right)^{-2.22}\left(\frac{v_{\text {int }}}{v_{\text {add }}}\right)^{-0.19}$

where $\boldsymbol{k}_{\mathbf{4}}=514.2 \mathrm{~s}$. These empirical equations show that increasing Reynolds number reduces the mixing time; that is speed up mixing. However the power of the Reynolds 


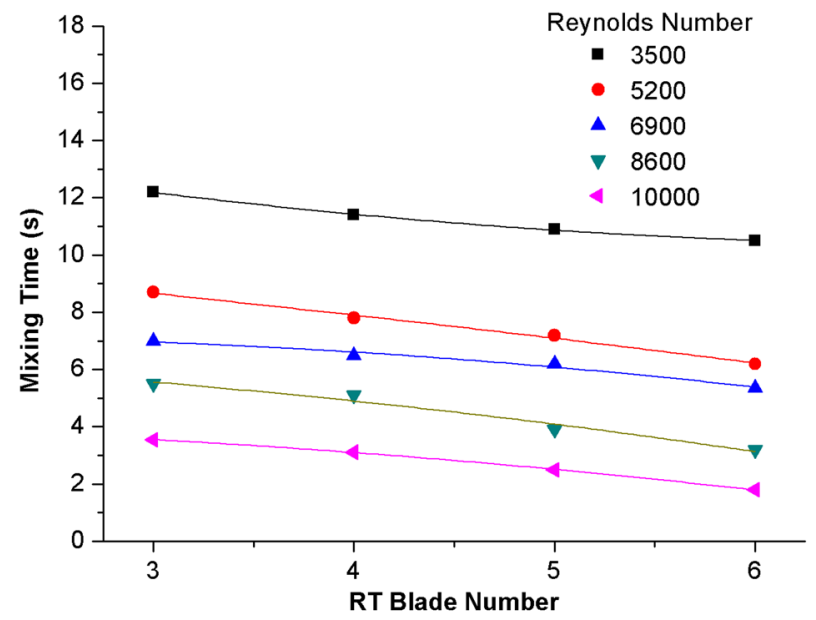

(a)

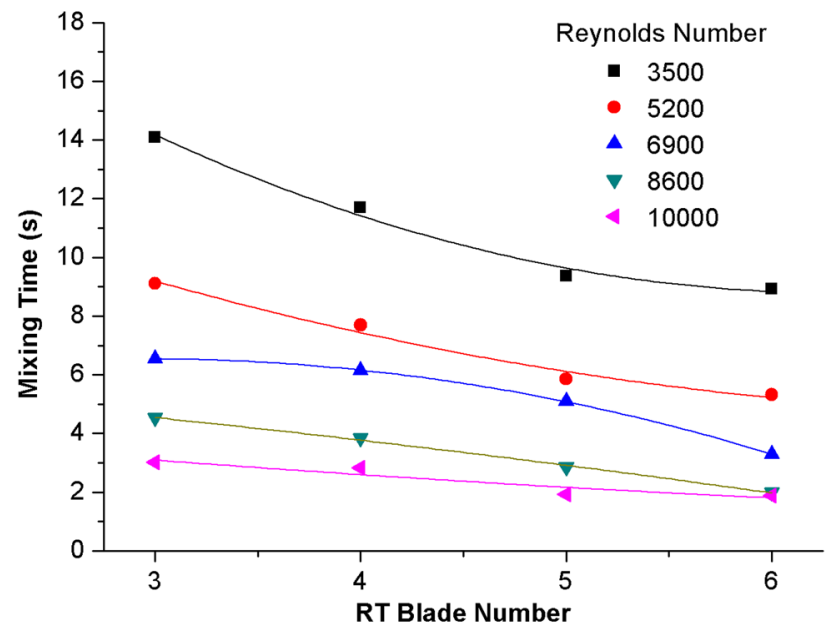

(b)

Fig. 8 Change in mixing time values with blade number at given Reynolds number for solutions a with no glycerol and b with $30 \%$ glycerol

number shows deviation from the expected value of -1.0 ; this can be attributed to the fact that correlation was developed on the basis of the properties of the initial and end solutions, separately, in the vessel, and that the Reynolds number changes after the addition of second solution depending upon the differences in their glycerol percentage. Furthermore, the measurements are local and they may not represent exactly the same behaviour as the global mixing time of the vessel. The most effective parameter is the volume ratio of the initial solution in the vessel. The correlation shows that when the initial amount of the solution is much more than the added one, that is as the amount of the added solution is smaller, the

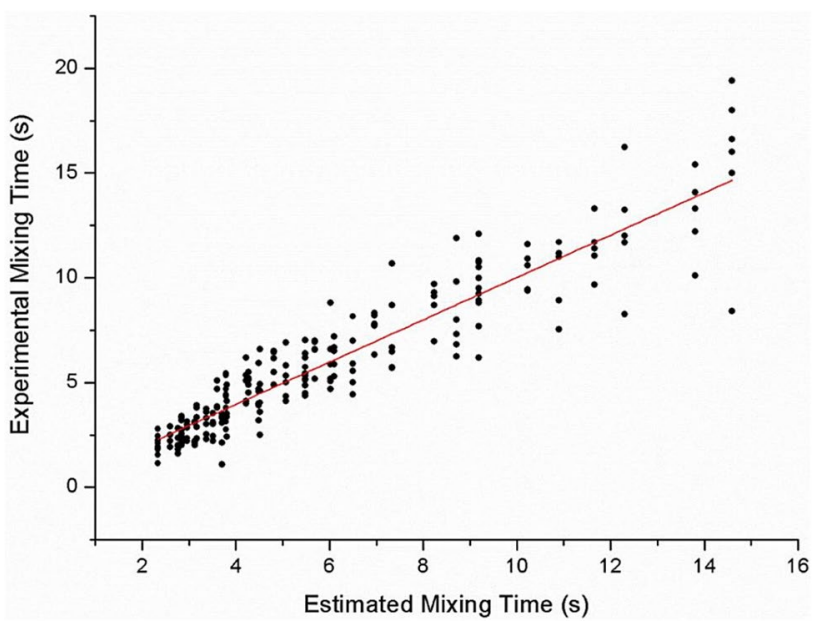

Fig. 9 Comparison of predicted values by Eq. (9) and experimental values of mixing time

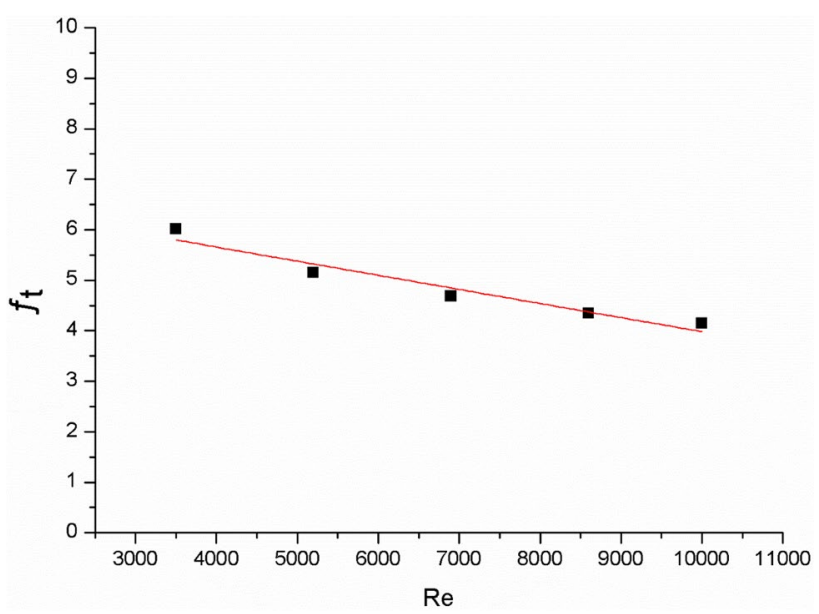

Fig. 10 Change of dimensionless mixing factor $f_{t}$ with $\operatorname{Re}$

mixing becomes faster. Moreover, when the difference between the kinematic viscosities of the initial and the added solutions is higher, the mixing gets faster as well, reducing mixing time. This behaviour reflects the effect of the density as well. This can be explained by that as the difference between the densities of the solution increases, the centripetal and centrifugal forces become more effective, thus speeding up the mixing.

The mixing time is effected by hydrodynamics of the system governed by a lot of parameters including the geometry of the system, the type of the agitators, type of blades, orientation of the agitators which can be concentrically or eccentrically oriented, shape of the vessel, 
Table 4 Mixing time values for solutions having different viscosity values for mixing in bulk volumes

\begin{tabular}{|c|c|c|c|c|}
\hline Exp. no & $\begin{array}{l}\text { Glycerol ratio of the } \\
\text { initial solution }(w / w)\end{array}$ & $\begin{array}{l}\text { Glycerol ratio of } \\
\text { added solution }(\mathrm{w} / \mathrm{w})\end{array}$ & $\begin{array}{l}\text { Volume ratio of } \\
\text { added solution (\%) }\end{array}$ & $\begin{array}{l}\text { Mixing time from } \\
\text { local cathode (s) }\end{array}$ \\
\hline 1 & 50 & 50 & 10 & 12.05 \\
\hline 2 & 50 & 50 & 20 & 15.45 \\
\hline 3 & 50 & 50 & 30 & 17.2 \\
\hline 4 & 50 & 30 & 10 & 6.75 \\
\hline 5 & 50 & 30 & 20 & 7.80 \\
\hline 6 & 50 & 30 & 30 & 14.10 \\
\hline 7 & 50 & 10 & 10 & 5.90 \\
\hline 8 & 50 & 10 & 20 & 7.68 \\
\hline 9 & 50 & 10 & 30 & 8.00 \\
\hline 10 & 30 & 50 & 10 & 5.69 \\
\hline 11 & 30 & 50 & 20 & 7.43 \\
\hline 12 & 30 & 50 & 30 & 10.23 \\
\hline 13 & 30 & 30 & 10 & 5.42 \\
\hline 14 & 30 & 30 & 20 & 6.90 \\
\hline 15 & 30 & 30 & 30 & 10.61 \\
\hline 16 & 30 & 10 & 10 & 6.24 \\
\hline 17 & 30 & 10 & 20 & 7.60 \\
\hline 18 & 30 & 10 & 30 & 8.57 \\
\hline 19 & 10 & 50 & 10 & 6.95 \\
\hline 20 & 10 & 50 & 20 & 7.30 \\
\hline 21 & 10 & 50 & 30 & 15.92 \\
\hline 22 & 10 & 30 & 10 & 4.03 \\
\hline 23 & 10 & 30 & 20 & 6.46 \\
\hline 24 & 10 & 30 & 30 & 7.95 \\
\hline 25 & 10 & 10 & 10 & 5.45 \\
\hline 26 & 10 & 10 & 20 & 6.65 \\
\hline 27 & 10 & 10 & 30 & 7.30 \\
\hline
\end{tabular}

flow regime of the mixed fluid. Therefore the values of the coefficient $k$ in Eqs. 9-13 will be depend upon the effect of these parameters, which is fairly complicated; it might differ depending upon the system characteristics similar to the coefficients in the empirical equations of heat/mass transfer. When these equations were developed as a function of the same variables with a slight change in system geometry, their coefficients differ greatly even though the flow regime and fluid characteristics were kept constant; in some instances, the coefficient has different values at different flow rate intervals without any change in flow regime and system geometry. Similarly, for example, for a system having a the same stirring speed range and vessel type as above, but with e different impeller type, the coefficient $k$ will probably be different when mixing time equation is developed as a function of the same variables.

\section{Conclusions}

This work was performed by employing a new measurement technique for mixing time; that is, the application of electrochemical limiting diffusion current technique to mixing time measurement, developed the first time by the authors [18]. The effects of some mixing parameters on the mixing time of a baffled vessel equipped with a Rushton turbine type impeller were measured and some empirical correlations were developed. According to the findings of the present work the following conclusions can be summarised;

- Increasing blade number and blade angle had a reducing effect of the mixing time. 
- Increasing Reynolds number reduced the mixing time.

- The developed empirical correlation showed that the most effective parameter for a faster mixing is Reynolds number with a power of -1.13 , which is very close to the values reported in the literature.

- The blade number was found to be more effective for reducing mixing time than blade angle in the investigated range.

- Dimensionless mixing factor values were found to be in very good agreement with those given in the literature.

- The local mixing time values for the solutions mixed in considerably higher proportions instead of adding trace amounts into the main solution showed that mixing time reduced with increasing Reynolds number, initial solution volume proportion and the ratio of the kinematic viscosity of the initial solution to that of the added one.

These results show that the electrochemical limiting current technique has a promising potential for mixing time measurements as a good, easy, simple, straightforward, fast and effective method.

Acknowledgements Thanks to Ataturk University for the support with the BAP Project No: 2013/343.

\section{Compliance with ethical standards}

Conflict of interest On behalf of all authors, the corresponding author states that there is no conflict of interest.

\section{References}

1. Paul EL, Atiemo-Obeng VA, Kresta SM (2004) Handbook of industrial mixing: science and practice. Wiley, Hoboken

2. Cullen PJ (2009) Food mixing: principles and applications. Wiley, Hoboken

3. Ghotli RA, Raman AAA, Ibrahim S, Baroutian S (2013) Liquidliquid mixing in stirred vessels: a review. Chem Eng Commun 200(5):595-627

4. Harnby N, Edwards M, Nienow AW (1997) Mixing in the process industries. Butterworth-Heinemann, Oxford

5. Zhang GA, Cheng YF (2009) Electrochemical corrosion of X65 pipe steel in oil/water emulsion. Corros Sci 51(4):901-907

6. Montante G, Mostek M, Jahoda M, Magelli F (2005) CFD simulations and experimental validation of homogenisation curves and mixing time in stirred Newtonian and pseudoplastic liquids. Chem Eng Sci 60(8-9):2427-2437

7. Jakobsen $\mathrm{H}$ (2008) Chemical reactor modeling. Springer, Berlin, pp 679-755
8. Doran PM (1995) Bioprocess engineering principles. Academic Press, Cambridge

9. Varzakas T, Polychniatou V, Tzia C (2014) Food engineering handbook: food process engineering. CRC Press, Boca Raton, pp 181-252

10. Bouwmans I, Bakker A, Van Den Akker HEA (1997) Blending liquids of differing viscosities and densities in stirred vessels. Chem Eng Res Des 75(8):777-783

11. Lee KC, Yianneskis M (1997) A liquid crystal thermographic technique for the measurement of mixing characteristics in stirred vessels. Chem Eng Res Des 75(8):746-754

12. Takahashi K, Motoda M (2009) Chaotic mixing created by object inserted in a vessel agitated by an impeller. Chem Eng Res Des 87(4):386-390

13. Delaplace G, Bouvier L, Moreau A, Guérin R, Leuliet J-C (2004) Determination of mixing time by colourimetric diagnosisapplication to a new mixing system. Exp Fluids 36(3):437-443

14. Zadghaffari R, Moghaddas J, Revstedt J (2009) A mixing study in a double-Rushton stirred tank. Comput Chem Eng 33(7):1240-1246

15. Holden $P$, Wang M, Mann R, Dickin F, Edwards R (1998) Imaging stirred-vessel macromixing using electrical resistance tomography. AIChE J 44(4):780-790

16. Alvarez MM, Guzmán A, Elías M (2005) Experimental visualization of mixing pathologies in laminar stirred tank bioreactors. Chem Eng Sci 60(8):2449-2457

17. Ascanio G (2015) Mixing time in stirred vessels: a review of experimental techniques. Chin J Chem Eng 23(7):1065-1076

18. Aydin Ö, Yapici S (2018) A novel method for the measurement of mixing time: a new application of electrochemical limiting diffusion current technique. Exp Therm Fluid Sci 99:242-250

19. Tatterson GB (1991) Fluid mixing and gas dispersion in agitated tanks. McGraw-Hill Companies, New York

20. Moo-Young M, Tichar K, Dullien FAL (1972) The blending efficiencies of some impellers in batch mixing. AIChE J 18(1):178-182

21. Geankoplis CJ (2003) Transport processes and separation process principles: includes unit operations. Prentice Hall Professional Technical Reference, Upper Saddle River

22. Wragg A (1977) Applications of the limiting-diffusion-current technique in chemical engineering. Chem Eng (Lond) 316:39-44

23. Selman JR, Tobias CW (1978) Mass-Transfer measurements by the limiting-current technique. In: Drew TB, Cokelet GR, Hoopes JW, Vermeulen T (eds) Advances in chemical engineering, vol 10, Chap 4. Academic Press, pp 211-318

24. Landau U (1981) In: AIChE symposium, series, vol 204, pp 75-87

25. Selman J (1981) In: AIChE symposium series (United States), vol 77. Illinois Institute of Technology, Chicago, pp 88-102

26. Böhm L, Jankhah S, Tihon J, Bérubé PR, Kraume M (2014) Application of the electrodiffusion method to measure wall shear stress: integrating theory and practice. Chem Eng Technol 37(6):938-950

27. Berger FP, Ziai A (1983) Optimisation of experimental conditions for electrochemical mass transfer measurements. Chem Eng Res Des 61(6):377-382

Publisher's Note Springer Nature remains neutral with regard to jurisdictional claims in published maps and institutional affiliations. 